\title{
Comparative Analysis of Fuzzy Expert Systems for Diabetic Diagnosis
}

\author{
Vishali Bhandari \\ Research Scholar \\ M.Tech (C.S.E), \\ DAVIET, Jalandhar, \\ Punjab, India
}

\author{
Rajeev Kumar \\ Assistant Professor, \\ Department of IT, \\ DAVIET, Jalandhar, \\ Punjab, India
}

\begin{abstract}
Diabetes is a situation when a body is not capable to produce insulin, which is needed to control glucose. Diabetes will also develop heart disease, kidney disease, blindness, nerve damage, and blood vessel damage. This paper uses Mamdanitype and Sugeno-type fuzzy expert systems for a diabetes diagnosis. Fuzzy expert system is a group of membership functions and rules. Fuzzy expert systems are tilting toward numerical processing. This paper recapitulates the essential distinction between the Mamdani-type and Sugeno-type fuzzy expert systems by using the input parameters such as age, obesity, RBS(Random Blood Sugar), family history and diet. The MATLAB fuzzy logic toolbox is used for the imitation of both the models. The accuracy, sensitivity, specificity and precision of the Mamdani-type fuzzy expert system is $95.48 \%, 96.36 \%, 93.33 \%$ and $97.24 \%$, respectively, and the accuracy, sensitivity, specificity and precision of the Sugenotype fuzzy inference system is $96.77 \%, 97.27 \%, 95.55 \%$ and $98.16 \%$, respectively.
\end{abstract}

\section{General Terms}

Expert system, fuzzy logic, membership function

\section{Keywords}

Diabetes; Mamdani; Sugeno, disease

\section{INTRODUCTION}

Fuzzy logic is a volitional set that holds up the feelings of an individual. Fuzzy logic comes into views at the globe in indefinite conditions to a large extent and individual mind takes in information then responds to accurate actions. Fuzzy system is exploded by Seiji Yasunobu and Soji Miyamoto of Hitachi, provided the advantage of fuzzy control systems for the Sendai railway. Its implications were accepted and were affianced to control speed up and braking. In Tokyo, Takeshi Yamakawa started the use of fuzzy control through simple constant fuzzy logic chips in an overturned pendulum test in 1987 but it is typical manages difficulty. Afterward Yamakawa gave an experiment by raising a wine tumbler having water to the peak of the pendulum. This method protected stability in both of the cases. Finally Yamakawa standardize his individual fuzzy-systems research laboratory to hold up his patents in the field. Fuzzy logic has some other applications such as medical expert systems, hand-printed character recognition, voice recognition, fuzzy automatic transmission system, auto focusing camera, automated space docking system, washing machine [24]. Diabetes is a situation when a body is not capable to produce insulin, which is needed to control glucose. Diabetes disease is not delighted well it can depart in front to cruel heath problems like heart disease, thoughtlessness, malfunction, kidney, etc. Diabetes is a continual disease in which the cells of the human body either do not respond accurately to insulin or insulin production becomes insufficient. So, it is essential to know how our body cells use glucose to produce power. According to biological process, the food distorted into glucose and generate power from glucose which helps the body cells to complete their tasks. In this process of power production a hormone called insulin is produced by the pancreas. The Insulin helps the body cells to absorb glucose. The diabetic patients cannot produce this hormone properly. So, it results in addition of glucose in the blood that causes diabetes. Diabetes has various general symptoms which include excessive thirst, frequent urination, hunger, weight loss, tiredness or weakness and vision problem. Diabetes is of two main types. These are type 1 and type 2 diabetes. Type 1 diabetes is known as insulin-dependent diabetes. In this type of diabetes, an individual's pancreas either constructs little insulin or it cannot construct any insulin. Patients with type 1 diabetes are about $10 \%$ of the population. This type of diabetes can be controlled by daily injections, meal planning, exercise and self-blood glucose monitoring. Type 2 diabetes is also known as non-insulin dependent diabetes. It is the regular type of diabetes. In type 2 diabetes, the pancreas produces insufficient insulin. It relates to the factors like age, obesity, family-history and lack of physical exercise [24]. Physical exercise, proper diet and insulin are the factors which help to recover from diabetes. As normal physicians do not have enough knowledge to deal with positive disease so, an expert is required for diabetic patients. But sometimes it is difficult for an individual to meet the expert. So, To resolve this problem, Knowledge based logical systems such as a fuzzy expert system can be appointed to reduce the number of deaths and the waiting time to meet the specialist. Fuzzy expert system is a system developed by collection of membership functions and rules is known as a fuzzy expert system. These functions and rules are used to reason about data. The Fuzzy systems are tilting toward numerical processing. The first step taken in the fuzzy expert system is known as fuzzification, which consider the numbers as input and then converts the input numbers in linguistic terms like low, Medium and high. After fuzzification by using fuzzy inference engine the rules are used to map the input linguistic terms onto similar linguistic terms that concerning the outcome. At last, the outcome linguistic terms are translated into an outcome number by the process known as defuzzification. To store these fuzzy rules and linguistic variable fuzzy knowledge base is used. Fuzzy expert systems have the capability to deal with inaccurate information. Fuzzy

expert system has two further types of expert system such as the Mamdani - type and sugeno-type fuzzy expert system. For confining the expert knowledge Mamdani method is frequently used. This method exhibits the knowledge in more insightful and human-like manner. Though, Mamdani-type fuzzy expert system engages a considerable computational trouble. In contrast, Sugeno-type fuzzy expert system does its job in a superior way with optimization and adaptive 
techniques and makes it computationally capable. These techniques make it very prominent in control difficulty, predominantly for dynamic non linear systems [16]. To adjust the membership functions these adaptive techniques are used so that fuzzy system most excellent molds the data. Mamdanitype and Sugeno-type fuzzy expert systems are different in the way the crisp outcome is generated from the fuzzy inputs. In the Mamdani-type fuzzy expert system fuzzy outcome is generated by the process called defuzzification and the Sugeno-type fuzzy expert system calculate the crisp outcome by using a weighted average. The important command and interpretability of Mamdani outcome is not available in the Sugeno fuzzy expert system while the outcome of the rules is not fuzzy. But Sugeno has recovered processing time as the weighted average reinstates the time overpowering defuzzification method. As the rule base has an interpretable and sensitive nature, Mamdani-type fuzzy expert system is largely used in decision support applications. Other distinctions are that Mamdani-type fuzzy expert system has outcome membership functions while Sugeno-type fuzzy expert system has no outcome membership functions [23] Mamdani-type fuzzy expert system is not flexible in system design in the negation of Sugeno-type fuzzy expert system as later can be integrated with adaptive Neuro fuzzy inference system to optimize the outcomes. This system can help the patients to know their problems and to recommend some initial treatment without consulting the physician. Though, the system is not planned to replace the specialist or experts. It is developed to help them in diagnosing their problems. Thus, these medical systems provide the way to reduce cost, time, human efforts and medical error.

Table 1. Comparison of Existing studies

\begin{tabular}{|c|c|c|c|c|}
\hline Author, Year & Disease Diagnosed & Technique Used & Input & Highlights \\
\hline $\begin{array}{c}\text { AKarahoca et } \\
\text { al(2009) }\end{array}$ & diagnosis of diabetes & $\begin{array}{c}\text { adaptive Neuro- } \\
\text { fuzzy inference } \\
\text { system } \\
\text { gender and shape of } \\
\text { the body }\end{array}$ & $\begin{array}{c}\text { age, cholesterol, } \\
\text { of diabetes disease and to find the } \\
\text { glucose rate in the blood. }\end{array}$ \\
\hline $\begin{array}{c}\text { H Temurtas et } \\
\text { al(2009) }\end{array}$ & Diabetic diagnosis & $\begin{array}{l}\text { Multi-layer neural } \\
\text { network approach }\end{array}$ & $\begin{array}{l}\text { Plasma goncentration, glucose } \\
\text { Diastolic blood } \\
\text { pressure, Body mass } \\
\text { index, Age }\end{array}$ & $\begin{array}{l}\text { The paper presents the comparative } \\
\text { study on diagnosis of pima Indian } \\
\text { diabetes disease by using multi-layer } \\
\text { neural network } \\
\text { approach } \\
\text { and }\end{array}$ \\
\hline $\begin{array}{c}\text { MA Kadhim } \\
\text { et al(2011) }\end{array}$ & Back pain diagnosis & Fuzzy expert system neural network. \\
\hline
\end{tabular}

\begin{tabular}{|c|c|c|c|c|}
\hline Authors, Year & Disease Diagnosed & Technique Used & Input & Highlights \\
\hline $\begin{array}{l}\text { Dr. Abdullah et } \\
\text { al(2011) }\end{array}$ & Type 1, type 2 diabetes & Cloud computing & $\begin{array}{l}\text { Diet, physical activity, } \\
\text { FPG test, OGTT test }\end{array}$ & $\begin{array}{l}\text { The expert system is designed for } \\
\text { diagnosis and determining the } \\
\text { treatment of diabetes and provide } \\
\text { the version for smart phones and i- } \\
\text { pads. }\end{array}$ \\
\hline $\begin{array}{l}\text { M.Kalpana and } \\
\text { Dr. A.V Senthil } \\
\text { Kumar(2012) }\end{array}$ & Diagnosis of diabetes & $\begin{array}{l}\text { Fuzzy assessment } \\
\text { methodology }\end{array}$ & 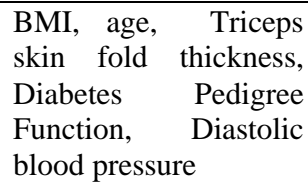 & $\begin{array}{l}90.38 \% \text { accuracy is achieved by } \\
\text { taking pima Indian dataset as the } \\
\text { dataset for the experiment of } \\
\text { diabetic diagnosis. }\end{array}$ \\
\hline $\begin{array}{l}\text { W } \\
\text { Luangruangrong } \\
\text { et al(2012) }\end{array}$ & $\begin{array}{l}\text { Risk factor of type } 2 \\
\text { diabetes }\end{array}$ & $\begin{array}{lr}\text { Back Propagation } \\
\text { Neural Network } \\
\text { approach and tuning } \\
\text { neural network }\end{array}$ & $\begin{array}{lr}\text { body mass index, } \\
\text { family-history, blood } \\
\text { pressure, } & \text { waist } \\
\text { circumference, } & \\
\text { smoking factor and } \\
\text { alcohol factor }\end{array}$ & $\begin{array}{l}\text { The study represents the risk factor } \\
\text { of type } 2 \text { diabetes of thai people } \\
\text { during } 2010 \text { to } 2012 \text { by using } \\
\text { different neural network } \\
\text { approaches. The accuracy of the } \\
\text { system is considered as } 84 \%\end{array}$ \\
\hline 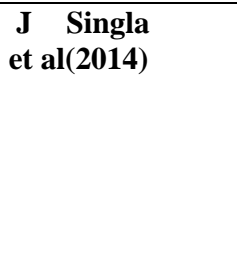 & $\begin{array}{l}\text { A review on } \\
\text { Diagnosis of different } \\
\text { diseases }\end{array}$ & $\begin{array}{l}\text { Fuzzy } \quad \text { expert } \\
\text { system, artificial } \\
\text { neural network }\end{array}$ & Age, BMI, symptom & $\begin{array}{l}\text { This review paper the author } \\
\text { presents the diagnosis of various } \\
\text { diseases by using the different } \\
\text { expert systems. The paper } \\
\text { describes that the performance of } \\
\text { system depends on the knowledge } \\
\text { base. }\end{array}$ \\
\hline
\end{tabular}




\section{RELATED WORK}

Most of the expert systems are developed by the different methods such as rule based expert system, fuzzy expert system, artificial neural network and adaptive Neuro fuzzy expert system for the diagnosis of various medical diseases based on clinical symptoms. In this study, the types of diabetes have been diagnosed by using a fuzzy expert system. In [4] the author uses adaptive Neuro-fuzzy inference system. For the diagnosis of diabetes by using the variables age, cholesterol, gender and shape of the body. This paper determines the efficiency of ANFIS by diagnosing diabetes and the estimation method to find glucose rate in the blood to diagnose diabetes risk. In [5] the authors compare multi-layer neural network and probabilistic neural network approach by using machine learning database. This paper is based on Pima Indian Diabetes. In [7] The fuzzy expert system is designed to diagnose back pain problem. All the data is taken on the basis of clinical observation. Input parameters of this paper areBMI, age and gender of the patient. These input parameters have membership functions such as (little, medium, high). Accuracy of the system is calculated in this research paper and it is $90 \%$. In [8] the author represents the treatment of diabetes by using cloud computing platform, "Google App Engine". In this paper authors diagnose diabetes with the help of two tests- fasting plasma glucose (FPG) and oral glucose tolerance test (OGTT). These tests show the condition of prediabetes, type 1 and type 2 diabetes. It has been expressed in [9] the paper is based on the fuzzy assessment methodology. This methodology uses fuzzy operators, membership functions, fuzzy logic and probability to manage uncertainty in rules. It has been expressed in [11] that the authors used Back Propagation Neural Network approach and tuning neural network to diagnose the risk factors of type 2 diabetes, having input factors like- body mass index, family-history, blood pressure, waist circumference, smoking factor and alcohol factor. The accuracy calculated in this paper is $84 \%$. In [18] the author describes the different expert systems in medical diagnosis. This paper describes that the performance of system depends on the knowledge base. So, there should have a greater stress on knowledge acquisition. In this review paper the author presents the diagnosis of various diseases by using the different expert systems such as fuzzy expert system artificial neural network.

\section{PROBLEM FORMULATION}

In India the main problem of Diabetes is the unawareness and carelessness among the people. So, the rate at which diabetes occur goes on increasing. Diabetes has further types- PreDiabetes, Type1 Diabetes, Type2 Diabetes. Pre-Diabetes and Type2 Diabetes have a very bad effect on health. The main reason is lack of knowledge of symptoms of diabetes. The diabetes problem mainly caused due to family _history, obesity, diet and age. Patients come to know about their disease when they are at the last stage. So, fuzzy medical expert system is required. So, that the patients, diagnose their disease in the early stages. The rate of diabetic patients is increasing at a rapid rate and the number of doctors is less. So, these medical expert systems are the blessings for the patients. Most of the researchers have diagnosed and determined the treatment of diabetes, but a little work is done for diagnosis of various types of diabetes such as pre- diabetes, type 1 diabetes, and type 2 diabetes. This paper provides the knowledge about the different types of diabetes to the patients easily and the system is designed for the diagnosis of different types of diabetes.

\section{PRESENT WORK \\ 4.1 Knowledge Acquisition}

In this study the objective of knowledge acquisition is to acquire the specific knowledge of diabetic diseases efficiently from medical experts. In this study, we have collected the data from civil hospital Jagraon for pre-diabetes, type1 and type 2 diabetic diseases by taking the input parameters age, obesity, RBS (random blood sugar), F_H(family history) and diet.

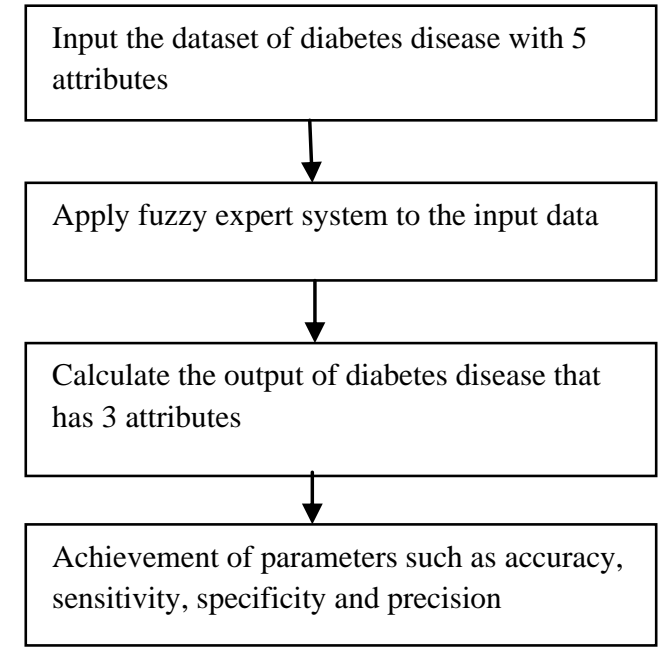

Fig.1 The Block diagram of present work

\subsection{Implementation of Mamdani-type fuzzy expert system}

Fuzzy system for identification of diabetes is primarily developed by using the Mamdani fuzzy model. It is made up of five inputs from Age, obesity, RBS(Random Blood Sugar), family history and diet. The Laboratory test using RBS provides all the symptoms of the patient. The system has one output that tells the types of diabetes. The different types of diabetes, measured in the Mamdani fuzzy-type inference system are pre-diabetes, type 1 diabetes and type 2 diabetes.

\subsection{Methodology of Mamdani-type Fuzzy inference System}

Step 1. Collect the data set from physicians.

Step 2. Make fuzzy expert system by making calls to the function FIS.

a) Do

b) Take dataset as input that was collected from physicians.

c) Perform fuzzification process by converting the input crisp values such as age, obesity, RBS, F_H, diet into linguistic variables like low, middle and high. [In this study, we consider trim for falsification]

d) Select the membership functions for various input values.

e) Generate the rules corresponding to these membership functions.

f) Perform defuzzification by converting linguistic variables into crisp value. 
g) Until all inputs classified correctly.

Step3. Evaluate the accuracy, sensitivity, specificity and precision of the system by making confusion matrix.

\subsection{Implementations of sugeno-type fuzzy expert system}

For diagnosis of different types of diabetes using sugeno-type model, the prelude steps are same as the Mamdani - type model. It also accepts input from age, family history, obesity, diet and Laboratory test using RBS and generates outcome that notify the type of diabetes.

\subsection{Methodology of sugeno-type Fuzzy inference System}

Step 1. Collect the data set from physicians.

Step 2. Make fuzzy expert system by making calls to the function FIS

a) $\quad$ Do

b) Take dataset as input that was collected from physicians.

c) Perform fuzzification process by converting the crisp values such as age, obesity, RBS, F_H, diet into linguistic variables like low, middle and high. [In this study, we consider trim for falsification]

d) Select the membership functions for various input values .

e) Generate the rules corresponding to these membership functions based on the equation

If Input $1=\mathrm{x}$ and Input $2=\mathrm{y}$,

Then Output $=\mathrm{f}($ input 1, input2)

f) Define the Firing Strength of each rule by the formula

$$
\mathrm{w}_{\mathrm{i}}=\text { And }\left(\mathrm{F}_{1}(\mathrm{x}), \mathrm{F}_{2}(\mathrm{y})\right)
$$

Where $F_{1}$ and $F_{2}$ are membership functions of input 1 and input The final value of the system is calculated as:

$$
\text { Final output }=\frac{\sum_{\mathrm{i}=1}^{\mathrm{N}} \mathrm{w}_{\mathrm{i}} \mathrm{z}_{\mathrm{i}}}{\sum_{\mathrm{i}=1}^{\mathrm{N}} \mathrm{w}_{\mathrm{i}}}
$$

g) Perform defuzzification by converting linguistic variables into crisp output.

h) Until all inputs classified correctly.

Step3.Evaluate the accuracy, sensitivity, specificity and precision of the system by making confusion matrix.

In sugeno-type model, output can be either constant or linear [22]. So, three membership functions for the outcome are prediabetes, type 1 diabetes and type 2 diabetes, which are constant and are shown in table I. The result of sugeno type fuzzy expert system will be in the range of 0-1.

Table2. Types of diabetes with constant values

\begin{tabular}{|c|c|c|}
\hline S.No & Types Of Diabetes & $\begin{array}{c}\text { Constant } \\
\text { Value }\end{array}$ \\
\hline 1. & Pre-Diabetes & 0 \\
\hline 2. & Type1 Diabetes & 0.5 \\
\hline 3. & Type2 Diabetes & 1 \\
\hline
\end{tabular}

\section{MEMBERSHIP FUNCTIONS OF MAMDANI-TYPE AND SUGENO- TYPE FUZZY EXPERT SYSTEM 5.1 Membership functions of input variables}

Both Mamdani-type and sugeno-type fuzzy expert systems have same input variables. The input variable age has to be taken within the ranges of 0 to 100 . The input variable RBS has to be taken within the ranges of 140 to 500 . Each of the two variables has three triangular membership functions as shown in fig 1 and 3 respectively. The input variable obesity has to be taken within the ranges of 15 to 40 having two membership functions as shown in fig 2 . The input variables Family history and diet have to be taken within the ranges of 0 to 1 each and have two triangular membership function as shown in fig 4 and 5 respectively.

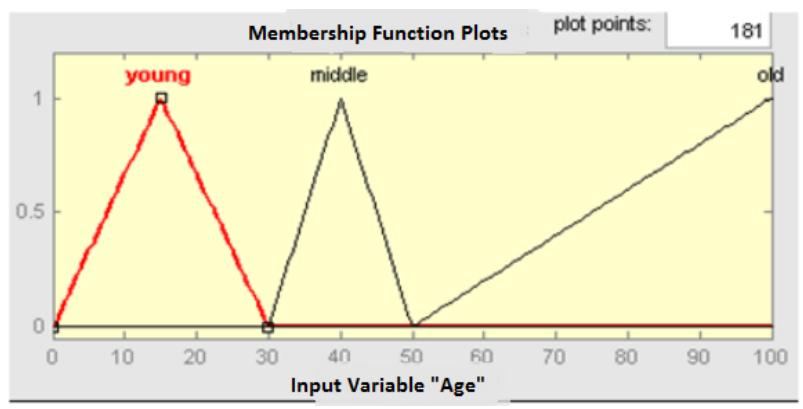

Fig.2 membership function of 'Age'

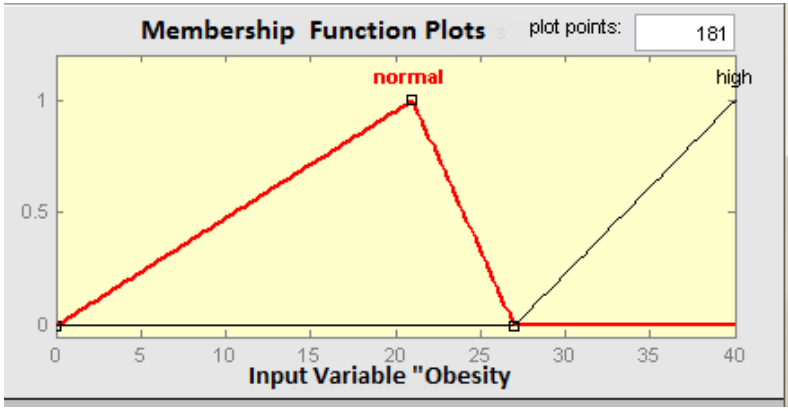

Fig.3 membership function of 'Obesity'

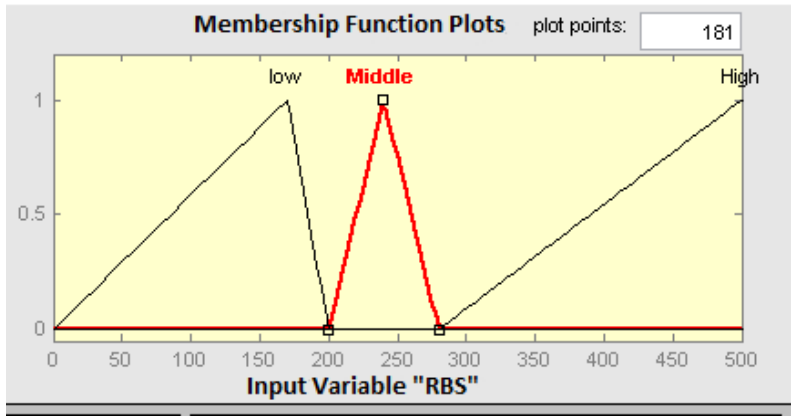

Fig.4 Membership function of 'RBS' 


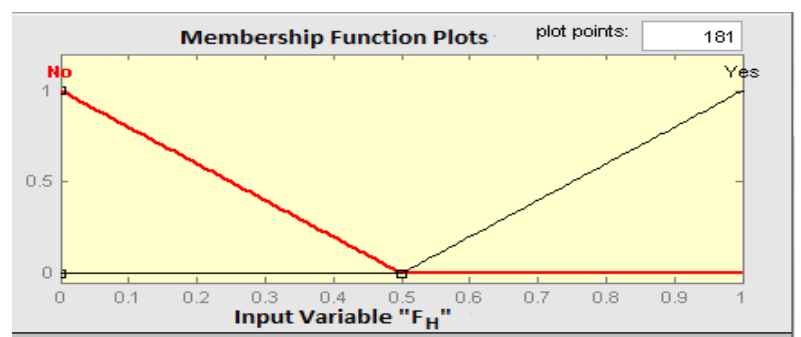

Fig.5 Membership function of ' $F_{-} H$ '

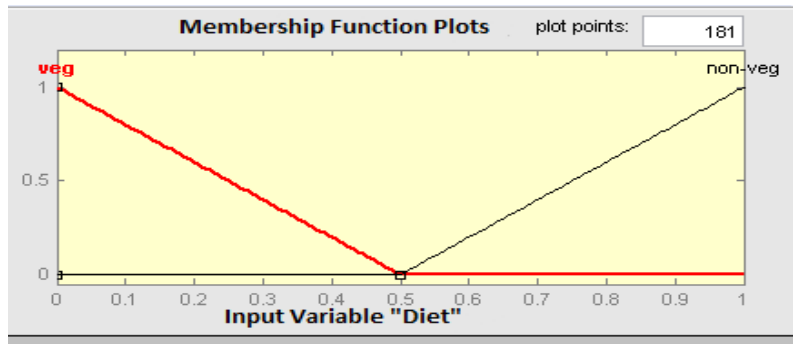

Fig.6 membership function of 'Diet'

\subsection{Membership functions of output variables}

The output variable types of diabetes have to be taken within the ranges of 0 to 100 and has three triangular membership functions in case of Mamdani-type fuzzy expert system as shown in fig 6 . The output variable has constant values in case of sugeno-type fuzzy expert system as shown in fig 7 .

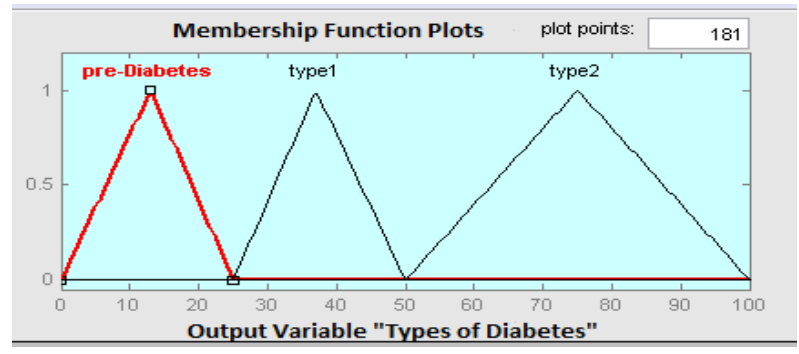

Fig.7 membership function of 'Types of Diabetes' of Mamdani-type fuzzy expert system

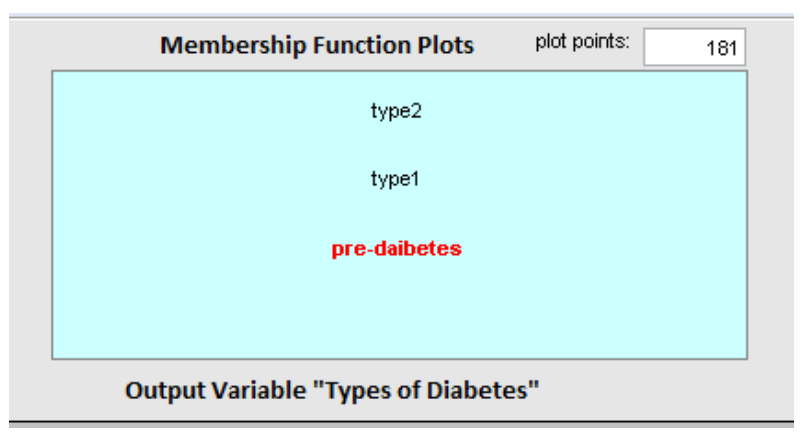

Fig.8 Membership function of 'Types of Diabetes' of sugeno-type fuzzy expert system

\section{RESULT ANALYSIS}

In this study different types of diabetes are categorized by using both Mamdani-type and sugeno-type fuzzy expert system that will be tested by the domain specialist categorize correctly and incorrectly by comparing systematic judgments with that of the domain specialist judgments reached on the same patient test cases. The performance of the system is usually estimated using the statistics in the matrix as shown in table 2 and 3 . On the basis of the confusion matrix the parameters calculated in this study are accuracy, sensitivity, specificity and precision by using the formula as follows.

$$
\begin{aligned}
& \text { Accuracy }=\frac{\mathrm{TP}+\mathrm{TN}}{\mathrm{TP}+\mathrm{TN}+\mathrm{FP}+\mathrm{FN}} \\
& \text { senstivity }=\frac{\mathrm{TP}}{\mathrm{TP}+\mathrm{FN}} \\
& \text { Specificity }=\frac{\mathrm{TN}}{\mathrm{TN}+\mathrm{FP}} \\
& \text { Precision }=\frac{\mathrm{TP}}{\mathrm{TP}+\mathrm{FP}}
\end{aligned}
$$

TP $($ True Positive Rate) $=$ It illustrates the records that are predicted as true as they are actually true.

TN $($ True Negative Rate) $=$ It illustrates the records that are predicted as false as they are actually false.

FP $($ False Positive Rate $)=$ It illustrates the records that are predicted as true as they are actually false.

FN (False Negative Rate) = It illustrates the records that are predicted as false as they are actually true.

Table3. Confusion matrix of Mamdani-type fuzzy expert system

\begin{tabular}{|l|l|l|l|}
\hline & $\begin{array}{l}\text { Pre- } \\
\text { diabetes }\end{array}$ & $\begin{array}{l}\text { Type1 } \\
\text { diabetes }\end{array}$ & $\begin{array}{l}\text { Type2 } \\
\text { diabetes }\end{array}$ \\
\hline $\begin{array}{l}\text { Pre- } \\
\text { diabetes }\end{array}$ & 42 & 01 & 02 \\
\hline $\begin{array}{l}\text { Type1 } \\
\text { diabetes }\end{array}$ & 02 & 45 & 03 \\
\hline $\begin{array}{l}\text { Type2 } \\
\text { diabetes }\end{array}$ & 02 & 03 & 55 \\
\hline
\end{tabular}

The total number of diagnosed patients taken from the above table is 155 . Out of these 155 in the second column, 45 diagnosed patients are of pre-diabetes from which 42 patients

cases are correctly categorized and 3 cases are incorrectly categorized. The third column shows the Patient cases of type 1 diabetes are taken as 50 , out of which 45 patient cases are categorized acceptably and the remaining 5 patient cases are categorized wrongly. In the fourth column the total 60 diagnosed patient cases, 55 are categorized as type 2 diabetes and 5 diagnosed patient cases are wrongly categorized. Based on the above formulas the accuracy, sensitivity, specificity and precision of the system is $95.48 \%, 96.36 \%, 93.33 \%$ and $97.24 \%$ respectively.

Table4. Confusion matrix of sugeno type fuzzy expert system

\begin{tabular}{|l|l|l|l|}
\hline & $\begin{array}{l}\text { Pre- } \\
\text { diabetes }\end{array}$ & $\begin{array}{l}\text { Type1 } \\
\text { diabetes }\end{array}$ & $\begin{array}{l}\text { Type2 } \\
\text { diabetes }\end{array}$ \\
\hline $\begin{array}{l}\text { Pre- } \\
\text { diabetes }\end{array}$ & 43 & 01 & 01 \\
\hline $\begin{array}{l}\text { Type1 } \\
\text { diabetes }\end{array}$ & 01 & 47 & 02 \\
\hline $\begin{array}{l}\text { Type2 } \\
\text { diabetes }\end{array}$ & 02 & 02 & 56 \\
\hline
\end{tabular}

The total number of diagnosed patients taken from the above table is 155 . The second column shows 45 diagnosed patients are of pre-diabetes from which 43 patients cases are correctly 
categorized and 2 cases are incorrectly categorized. The third column shows the Patient cases of type 1 diabetes are taken as 50 , out of which 47 patient cases are categorized acceptably and the remaining 3 patient cases are categorized wrongly. In the fourth column the total 60 diagnosed patient cases, 56 are categorized as type 2 diabetes and 4 diagnosed patient cases are wrongly categorized. Based on the above formulas the accuracy, sensitivity, specificity and precision of the system is $96.77 \%, 97.27 \%, 95.55 \%$ and $98.16 \%$ respectively.

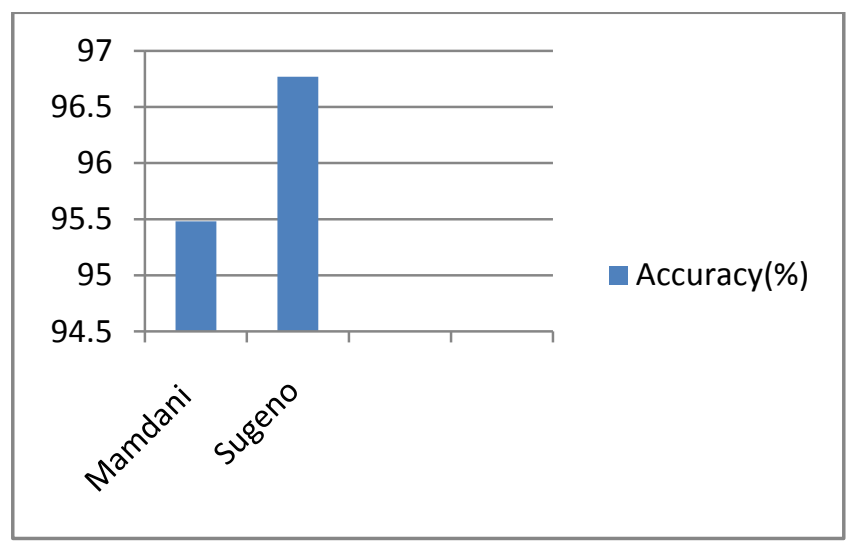

Fig. 9 comparison graph of Accuracy

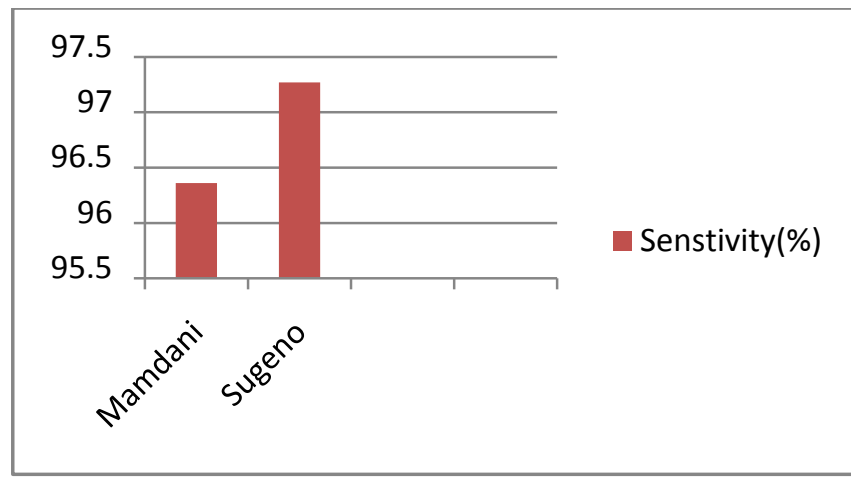

Fig.10 Comparison graph of sensitivity

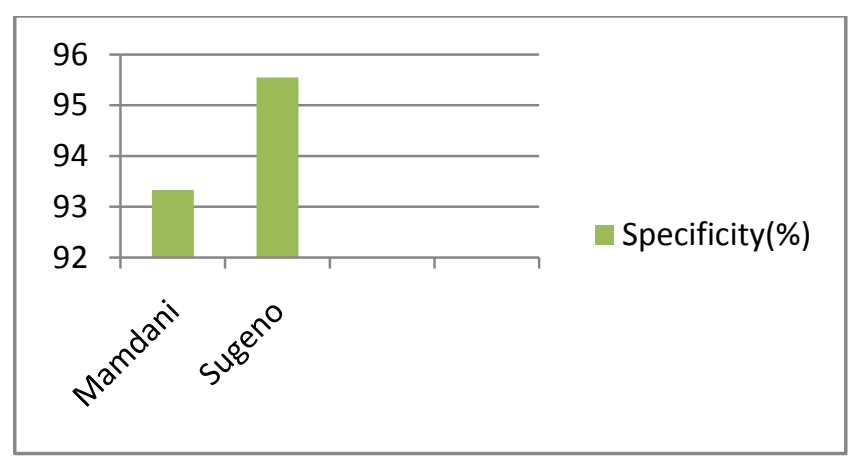

Fig.11 Comparison graph of specificity

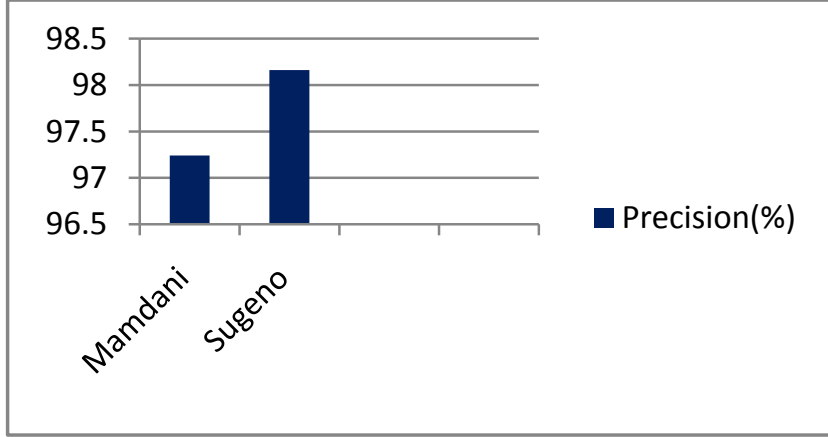

Fig.12 Comparison graph of precision

Accuracy, sensitivity, specificity and precision are obtained by using both the fuzzy expert systems and results are shown in the graph above. The output of Sugeno-type fuzzy expert system is either constant or linear. This is the reason that the results achieved in Sugeno-type fuzzy expert system are better.

\section{CONCLUSION}

Today, diabetes is flattering the fat epidemic in India with 62 million and more diabetic persons. Not only in India but all over the world is losing the fight next to diabetes. International diabetes federation (IDF) recognizes that nearly $52 \%$ of Indian individuals are suffering from diabetes and they are not aware with their problem. Fuzzy expert system is widely used to diagnose the diabetic disease. Most of the research work is done on diabetes in general, but not particularly in its types. A few researchers work on the types of diabetes. In this paper the fuzzy expert system for diagnosis of diabetes using Mamdani and Sugeno models is implemented successfully and results in both the cases are achieved. From the results it is concluded that the accuracy in case of sugeno-type fuzzy expert system is quite more than Mamdani-type fuzzy expert system. Also, the other parameters such as sensitivity, specificity and precision are better in case of sugeno-type fuzzy expert system rather than mamdani-type fuzzy expert system.

\section{ACKNOWLEDGMENT}

I wish to express sincere thanks for sh. Rajeev Vashisth, Asst. Prof, D.A.V College, Jalandhar, for guiding throughout the present research work. I wish to express thanks to the staff of the Department of Information and Technology for their sensible help and support. I intend sincere thanks to Dr. Manoj Kumar, Principal of the institution for providing all the necessary facilities for this research work. Last but not the least I am grateful to my parents for the interminable help, encouragement, support and attention.

\section{REFERENCES}

[1] Antenna W., "Prototype knowledge Based System in Antiretroviral Therapy", MSc Thesis, Addis Ababa University School of Information Science, Ethiopia, 2004.

[2] Artificial Intelligence Expert Systems Rule-based expert systems and CLIPS Other approaches to knowledge representation: Semantic networks and frames Common sense reasoning: $\mathrm{CYC}$

[3] K Polat, S Güne, "An expert system approach based on principal component analysis and adaptive Neuro-fuzzy inference system to a diagnosis of diabetes disease", Electrical and Electronics Engineering Department, 
Selcuk University, 42035 Konya, Turkey, Elsevier, Digital Signal Processing 17 (2007) 702-710

[4] A Karahoca, D Karahoca, A Kara, "Diagnosis of Diabetes by using Adaptive Neuro Fuzzy Inference Systems", (C2009 IEEE

[5] H Temurtas, N Yumusak, F Temurtas, "A comparative study on diabetes disease diagnosis using neural networks", Elsevier, Expert Systems with Applications 36 (2009) 8610-8615

[6] B Pandey, R.B.Mishra, "Knowledge and intelligent computing system in medicine", Elsevier, Computers in Biology and Medicine 39 (2009) 215 - 230

[7] M A Kadhim, M.A Alam, H Kaur, "Design and Implementation of Fuzzy Expert System for Back pain Diagnosis", International Journal of Innovative Technology \& Creative Engineering (ISSN:2045-8711) Vol.1 No.9 SEPTEMBER 2011

[8] Dr. Abdullah Al-Malaise Al-Ghamdi et al, "An Expert System of Determining Diabetes Treatment Based on Cloud Computing Platforms" International Journal of Computer Science and Information Technologies, Vol. 2 (5), 2011, 1982-1987

[9] M.Kalpana, Dr. A.V Senthil Kumar, "Design and implementation of Fuzzy Expert System using Fuzzy Assessment Methodology", Volume 1, No.1, March April 2012 International Journal of Science and Applied Information Technology

[10] T S Zeki, et al., "An Expert System For Diabetes Diagnosis", American Academic and Scholarly Research Journal Special Issue, Vol. 4, No.5, Sept 2012

[11] W Luangruangrong, A Rod took, S Chimmanee, "Study of Type 2 Diabetes Risk Factors Using Neural Network For Thai People and Tuning Neural Network Parameters", 2012 IEEE International Conference on Systems, Man, and Cybernetics, October 14-17

[12] A. Kaur and A. Kaur, "Comparison of Mamdani-type and sugeno-type fuzzy inference systems for air conditioning system”, IJSCE, Vol. 2, issue2, 2012.

[13] D pal et al," Fuzzy expert system approach for coronary artery disease screening using clinical parameters" Knowledge-Based Systems 36 (2012) 162-174

[14] M Peyrot et al, "Diabetes Attitudes, Wishes and Needs 2 (DAWN2): A multinational, multi-stakeholder study of psychosocial issues in diabetes and person-centered diabetes care", Elsevier, diabetes research and clinical practice 99 (2013) $174-184$

[15] C S, Pereira, "DNA damage and cytotoxicity in adult subjects with prediabetes", Elsevier, Mutation Research 753 (2013) 76- 81

[16] B J Lee et al, "Prediction of Fasting Plasma Glucose Status Using Anthropometric Measures for Diagnosing Type 2 Diabetes", IEEE JOURNAL OF BIOMEDICAL AND HEALTH INFORMATICS, VOL. 18, NO. 2, MARCH 2014

[17] J W Chung et al, "Screening for pre-diabetes using support vector machine model", 2014 IEEE

[18] J Singla, D Grover, A Bhandari," Medical Expert Systems for Diagnosis of Various Diseases", International Journal of Computer Applications (0975 8887) Volume 93 - No.7, May 2014

[19] J Singla, "Comparative Study of Mamdani-Type and Sugeno-Type Fuzzy Inference Systems for Diagnosis of Diabetes", 2015 International Conference on Advances in Computer Engineering and Applications (ICACEA) IMS Engineering College, Ghaziabad, India

[20] www.disabled-world.com/health/diabetes/

[21] www.bupa.co.uk/health-information/directory/t/type-1diabetes

[22] www.ncbi.nlm.nih.gov/pubmedhealth/PMH0002194/

[23] www.articlesofhealthcare.com/80/types-of-diabetesmellitus-1-2gestational.htm 